\title{
AS ÁREAS PROTEGIDAS DO SISTEMA PRODUTOR DO ALTO TIETÊ: A GOVERNANÇA E O PLANEJAMENTO EM CENÁRIOS DE MUDANÇAS CLIMÁTICAS
}

\author{
Solange Alves Duarte dos Santos ${ }^{1}$ \\ Sandra Momm Schult ${ }^{2}$ \\ Luciana Rodrigues Fagnoni Costa Travassos ${ }^{3}$ \\ Bruna de Souza Fernandes ${ }^{4}$
}

\section{RESUMO}

Objetivo: compreender como as áreas protegidas dialogam com instrumentos de governança, como se inserem no planejamento territorial nas várias escalas e nas políticas setoriais e qual seu potencial para enfrentamento das mudanças climáticas no SPAT - Sistema Produtor do Alto Tietê.

Referencial teórico: a governança das áreas protegidas são interações entre estruturas, processos e tradições que determinam como o podere as responsabilidades são exercidos. São relações entre múltiplos atores, instituições e temas, que expressam arranjos entre interesses e possibilidades de negociação, para prevalência do bem comum, relacionada com a implementação socialmente aceitá velde políticas públicas.

Método: a partir de dados de pesquisa sobre o SPAT, do conhecimento a dquirido com práticas de pla neja mento, registros pessoais e pesquisa documental. É um estudo de ca so sobre aplicação dos instrumentos de pla neja mento e governança, as áreas protegidas, que analisa impactos e transformações na produção do espaço e a condição de implementação da legislação das área s protegidas no SPAT.

Resultados e conclusão: as áreas protegidas são estra tégicas para mitigação das mudanças climáticas. Sua governa nça é tema chave, aplicada tanto na gestão das unidades de conservação quanto dos mananciais hídricos. As mudanças climáticas já são realidade no SPAT, sendo importante, portanto, pensar estratégias de mitigação e adaptação diante de tais cenários.

Implicações da pesquisa: analisando o SPAT, afirma-se que as áreas protegidas são instrumentos articuladores e integra dores para proteção a mbientale desenvolvimento susten tável.

Originalidade/valor: aliando a pesquisa à prática de planejamento e gestão, o estudo propõe contribuir com o debate sobre a governança dos recursos hídricos e a proteção a mbiental, analisando as áreas protegidas do SPAT em cenários de mudanças climáticas.

PALAVRAS-CHAVE: Áreas Protegidas. Unidades de Conservação. Governança. Mudanças Climáticas. Alto Tietê.

\footnotetext{
${ }^{1}$ Doutoranda em "Planejamento e Gestão do Território", pela Universidade Federal do ABC-SP, São Paulo (Brasil). Email: duartelange@gmail.com Orcid: https://orcid.org/0000-0002-7226-1969

2 Pós-doutora do pelo Department of European Planning Cultures - Faculty of Spatial Planning - Technical University of Dortmund (Alemanha). Email: sandramomm@gmail.com Orcid: https://orcid.org/0000-0002-9724-5375

3 Mestrado em Ciências Ambientais pela Universidade de São Paulo - USP, São Paulo (Brasil). Email: luciana.travassos.ufabc@gmail.com Orcid: https://orcid.org/0000-0001-8369-8704

4 Bacharel em Ciências e Humanidades Universidade Federal do ABC-SP, São Paulo (Brasil). Email: bsfernandes17@gmail.com Orcid: https://orcid.org/0000-0002-4419-4842
} 


\title{
THE PROTECTED AREAS OF THE UPPER TIETÊ PRODUCTION SYSTEM: GOVERNANCE AND PLANNING IN CLIMATE CHANGE SCENARIOS
}

\begin{abstract}
Purpose: understand how protected areas dialogue with governance instruments, are inserted in territorial planning at various scales and in sectorial policies, and their potential for confronting climate change in the SPAT-System Producer do Alto Tietê.

Theoretical framework: the governance of protected areas are interactions between structures, processes and traditions that determine how power and responsibilities are exercised. They are relationships between multiple actors, institutions and themes, which express arrangements between interests and negotiation possibilities, for the prevalence of the common good, related to the socially acceptable implementation of public policies.

Method/design/approach: from SPAT research data, from knowledge gained from planning practices, personal records and document research. It is a case study on the application of planning and governance instruments, the protected a reas, which analyzes impacts and transformations in the production of space and the condit ion of implementation of legislation on protected areas in SPAT.
\end{abstract}

Results and conclusion: protected areas a re strategic for mitigating climate change. Its governance is a key issue, applied both to the management of conservation units and water sources. Climate change is already a reality in SPAT, and it is important to think about mitigation and adaptation strategies in view of such scenarios.

Research implications: analyzing the SPAT, it is stated that protected areas a re articulating and integrating ins truments for environmental protection and sustainable development.

Originality/value: combining research with the practice of planning and management, the study proposes to contribute to the debate on the governance of water resources and environmentalprotection, analyzing the SPAT protected areas in climate change scenarios.

Keywords: Protected Areas. Conservation units. Governance. Climate changes. Alto Tietê. 
Duarte dos Santos, S. A. ., Momm Schult, S., Travassos, L. R. F. C. ., \& Fernandes, B. de S. . (2021). As Áreas Protegidas do Sistema Produtor do Alto Tietê: A Governança e o Planejamento em Cenários de Mudanças Climáticas.

\section{INTRODUÇÃO}

$\mathrm{O}$ artigo analisa o papel das áreas protegidas, enquanto instrumento de planejamento e governança em cenário de mudanças climáticas, na sub-região do Alto Tietê-Cabeceiras, da Unidade de Gerenciamento de Recursos Hídricos do Alto Tietê, localizada na Região Metropolitana de São Paulo, com foco no Sistema Produtor do Alto Tietê (SPAT). As áreas protegidas cumprem um importante papel nas políticas públicas enquanto instrumento de planejamento territorial e governança ambiental.

Dentre as estratégias mais eficientes para mitigação dos efeitos das mudanças climáticas é possível destacar a implantação de áreas protegidas, pela função de conter o desmatamento e proverem uma série de serviços ecossistêmicos, como os de regulação (Jantz et al., 2014). Com as discussões relacionadas às mudanças climáticas, a implantação e a gestão das áreas protegidas ganham força. Destacam-se, nesse contexto, as Unidades de Conservação, tipologias de áreas especialmente protegid as estabelecidas pelo Sistema Nacional de Unid ades de Conservação (SNUC), que são territórios de planejamento, participação e governança, complexos, multiníveis e multiescalares.

O conceito de governança para as áreas protegidas foi definido por Graham, Amos e Plumptre (2003) como a arena em que "as interações entre estruturas, processos e tradições [...] determinam como o poder e as responsabilidades são exercidos, como as decisões são tomadas; afirmam que se trata de poder e de como os tomadores de decisão são responsabilizados" (Graham, Amos \& Plumptre, 2003, p. 8). Os autores sugerem cinco princípios fundamentais de boa governança para áreas protegidas, com base na lista do Programa das Nações Unidas para o Desenvolvimento, a saber: legitimidade e voz, direcionamento, desempenho, prestação de contas e equidade. Tais princípios foram adotados pelo documento final do VI Congresso Mundial de Parques, Internacional Union for Conservation of Nature - IUCN, em Durban, 2003, como recomendação para a "boa governança" nos processos de gestão dessas áreas. No caso das Unid ades de Conservação no Brasil é possível encontrar tais princípios em seus marcos legais

A área de estudo deste trabalho (figura $n^{\circ} 1$ ) é o Sistema Produtor do Alto Tietê e a Área de Proteção e Recuperação dos Mananciais do Alto Tietê Cabeceiras (APRM-ATC), na sub-região Alto Tietê-Cabeceiras, Região Metropolitana de São Paulo. O SPAT é um conjunto de bacias de reservatórios protegidos para abastecimento público que envolve: Mogi das Cruzes, Suzano, BiritibaMirim e Salesópolis. Encontra-se numa região de grande desenvolvimento econômico e que possui função estratégica do ponto de vista ambiental, pois para além de ser Área de Proteção e Recuperação de Mananciais (APRM), faz parte da Reserva da Biosfera do Cinturão Verde da Cidade de São Paulo (RBCV). Declarad a pela UNESCO em 9 de junho de 1994, as Reservas da Biosfera são uma categoria internacional de área protegida prevista no art. 41 do SNUC. Assim, a região abriga várias áreas protegidas e grandes remanescentes de Mata Atlântica e é, ainda, um território com múltiplos significados culturais e simbólicos, no qual as relações e conflitos por acesso a recursos e a disputa pelo seu controle são marcantes.

Para além da complexidade inerente à governança das áreas protegidas, nesta região, esta se articula com a governança da água, bem como com a governança urbana/metropolitana, o que torna importante a aproximação entre as Políticas Ambiental, de Recursos Hídricos e de Gestão Urbana/Metropolitana. Neste caso, para o alcance de resultados socioambientais em termos de bemestar humano e proteção ecossistêmica, é essencial o estabelecimento de estratégias de gestão integrada entre as diversas esferas para a construção de agendas comuns e pactuações; estratégias que podem ser consideradas práticas multiescalares e parte de uma governança multinível.

O Plano Nacional de Áreas Protegidas - PNAP (Decreto Federal no 5.758/2006) reconhece a importância da integração do sistema de áreas protegidas com o sistema de recursos hídricos, a partir de um sistema de práticas integradas com a gestão das bacias hidrográficas, VI - as áreas protegidas devem ser apoiadas por um sistema de práticas de manejo sustentável dos recursos naturais, 
integrado com a gestão das bacias hidrográficas (anexo - 1.2, VI) $e$ marcam a grande importância das áreas protegidas para o ordenamento territorial, $X X$ - incluir a criação de áreas protegidas na formulação e implementação das políticas de ordenamento territorial e de desenvolvimento regional (anexo - 1.2, XX) (Brasil, 2006).

Nesse sentido, as interações locais no desenvolvimento de programas, projetos e ações precisam articular territórios para proteção. Tal constatação aponta para a necessidade de entendimento das dinâmicas desta região, em que as relações de poder são influenciadas por muitos fatores e diversos interesses, com atores ativamente engajados em diversas escalas e com influência contínua na tomada de decisão.

Assim, pretende-se compreender de que forma as áreas protegidas dialogam com outros instrumentos de governança ambiental, como se inserem no planejamento territorial em suas várias escalas e nas demais políticas setoriais, bem como seu potencial para enfrentar as mudanças climáticas. O texto está organizado em quatro seções, para além desta introdução e a conclusão. A primeira apresenta de forma breve as áreas protegidas no Brasil e os processos de governança no SPAT. A segunda seção aborda as mudanças climáticas e os processos de governança das áreas protegidas. A terceira seção apresenta as áreas protegidas no contexto do SPAT, destacando a importância das Unidades de Conservação Municipais e a quarta faz uma breve análise do território em estudo.

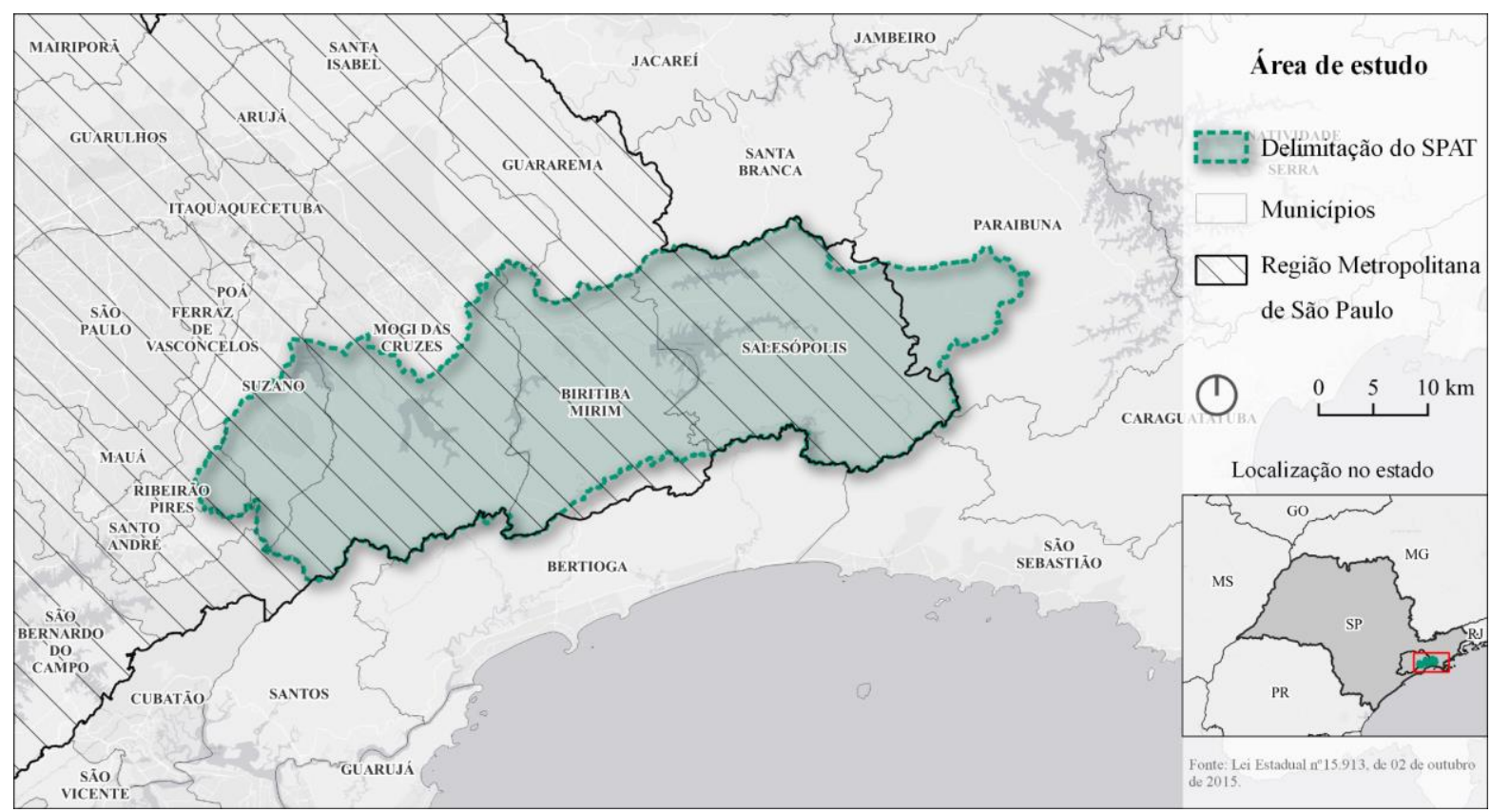

Figura $n^{\circ} 01$ - Mapa da área de estudo.

Fonte: LAPLAN, Bruna Fernandes, 2021.

\section{BASES TEÓRICAS E NORMATIVAS DOS ESPAÇOS TERRITORIALMENTE PROTEGIDOS PARA O CASO EM ESTUDO}

Historicamente, a criação de áreas protegid as tem como motivação a necessid ade de limitação das atividades humanas no território, de forma a minimizar os impactos ambientais, ou mesmo para proteção de áreas de relevante beleza cênica, para fins de interesses turísticos, proteção de recursos hídricos ou por abrigarem espécies-símbolos. Muitas vezes sua constituição nasce da pressão da 
Duarte dos Santos, S. A. ., Momm Schult, S., Travassos, L. R. F. C. ., \& Fernandes, B. de S. . (2021). As Áreas Protegidas do Sistema Produtor do Alto Tietê: A Governança e o Planejamento em Cenários de Mudanças Climáticas.

sociedade civil, no entanto, há influência direta dos interesses políticos e econômicos que devem ser considerados em todo o processo de estabelecimento de uma área protegida.

O termo "área protegida" é aceito e adotado mundialmente e foi definido pela International Union Conservation for Nature (IUCN) desde 1994 como: "uma superfície de terra ou mar especialmente consagrada à proteção e à manutenção da diversidade biológica, assim como dos recursos culturais associados, e dirigida através de meios jurídicos e de outros meios eficazes, áreas estas que devem ser destinadas essencialmente à conservação da biodiversidadee devem ser definidas legalmente". Para a Convenção da Biodiversidade (1992), as áreas protegidas são espaços definidos geograficamente que se destinam ou são regulamentadas e administradas para alcançar objetivos específicos de conservação.

No Brasil, a previsão legal da competência do poder público para a criação dos espaços protegidos é estabelecida na Constituição Federal de 1988 (art. 225, § 1o, inciso III) (Brasil, 1988), na Lei no 6.938/1981 (Brasil, 1981, art. 9o) e na Lei Complementar (LC) no 140/2011 (Brasil, 2011, art. 7o, inciso X; art. 8o, inciso X; art. 9o, inciso X) (Momm et al, 2021). O estabelecimento do sistema de áreas protegidas brasileiro baseou-se em diferentes modelos e convenções internacionais e incluem as Unidades de Conservação, estabelecidas na Lei no 9.985/2000 - Sistema Nacional de Unidades de Conservação (SNUC), e áreas correlatas, sendo: Áreas de Preservação Permanente, Áreas de Reserva Legal, Áreas de Mananciais, Reservas da Biosfera, Áreas Tombadas, Territórios Indígenas e Quilombolas, entre outras.

De acordo com Bensusan (2006), o Código Florestal de 1934 introduziu a figura de "unidade de conservação", subdividindo-a em três categorias: as florestas protetoras, em domínios privados, as florestas remanescentes, em terras públicas e uma terceira categoria chamada de florestas de rendimento (Bensusan, 2006).

O conceito "unidade de conservação" foi incorporado ao art. $2^{\circ}$ do SNUC, como: "espaço territorial e seus recursos ambientais, incluindo as águas jurisdicionais, com características naturais relevantes, legalmente instituído pelo Poder Público, com objetivos de conservação e limites definidos, sob regime especial de administração, ao qual se aplicam garantias adequadas de proteção" (SNUC, 2000).

O SNUC integra sob um único marco legal, as áreas protegidas denominadas Unidades de Conservação, dos três entes da Federação (Federal, Estadual e Municipal). Contempla, entre outros aspectos, a conservação da biodiversidade, a proteção de bacias hidrográficas, as paisagens, a recreação, o turismo, a conservação de sítios históricos, arqueológicos e culturais. Está organizado em dois grandes grupos, que abrangem diferentes categorias, sendo: grupo I - Unidades de Proteção Integral, que tem como objetivo preservar a natureza, send o admitido apenas o uso ind ireto dos seus recursos naturais, com exceção dos casos previstos na lei, estando neste grupo: Estação Ecológica, Reserva Biológica, Parque Nacional, Estadual ou Natural (Municipal), Monumento Natural e Refúgio da Vida Silvestre. E o grupo II - Unidades de Uso Sustentável, com objetivo de compatibilizar a conservação da natureza com o uso sustentável de parcela dos seus recursos naturais, estando neste grupo: Área de Proteção Ambiental, Área de Relevante Interesse Ecológico, Floresta Nacional, Reserva Extrativista, Reserva de Fauna, Reserva de Desenvolvimento Sustentável e Reserva Particular do Patrimônio Natural.

Além das UCs previstas no SNUC, existem ainda outras tipologias de áreas protegidas, estabelecidas em outros instrumentos legais, como: Área de Preservação Permanente e Área de Reserva Legal - instituídas pela Lei Federal no 12.651/2012; Área de Proteção de Mananciais e Área de Proteção e Recuperação de Mananciais - instituídas nas Leis Estaduais n n 898/75, nº 1.172/76 e nº 9.866/97, entre outras.

De acordo com o novo Código Florestal (Lei Federal no 12.651/2012), a área de preservação permanente: é uma área protegida, coberta ou não por vegetação nativa, com a função ambiental de preservar os recursos hídricos, a paisagem, a estabilidade geológica e a biodiversidade, facilitar o fluxo gênico de fauna e flora, proteger o solo e assegurar o bem-estar das populações humanas (art. 
Duarte dos Santos, S. A. ., Momm Schult, S., Travassos, L. R. F. C. ., \& Fernandes, B. de S. . (2021). As Áreas Protegidas do Sistema Produtor do Alto Tietê: A Governança e o Planejamento em Cenários de Mudanças Climáticas.

$3^{\circ}$ - II). Assim, temos: vegetação marginal ao longo de rios, ao redor de lagos, lagoas, reservatórios, nascentes; vegetação de topos de morros, morrotes, montanhas e serras, vegetação de encostas com declividade superior à $45^{\circ}$; vegetação de restingas e mangues, entre outras. A mesma lei traz como definição para reserva legal: área localizad a no interior de uma propriedade ou posse rural, delimitada nos termos do art. 12, com a função de assegurar o uso econômico de modo sustentável dos recursos naturais do imóvel rural, auxiliar a conservação e a reabilitação dos processos ecológicos e promover a conservação da biodiversidade, bem como o abrigo e a proteção de fauna silvestre e da flora nativa (art. $3^{\circ}-$ III).

No Estado de São Paulo, as Áreas de Proteção aos Mananciais foram estabelecidas para proteção dos sistemas produtores de água e para o disciplinamento do uso do solo, para proteção dos mananciais, reservatórios e cursos d'água de interesse para o abastecimento da Região Metropolitana de São Paulo. A delimitação abrangeu quase 100\% do território em alguns municípios do SPAT, tais como Biritiba-Mirim (89\%) e Salesópolis (98\%) e, no caso de Mogi das Cruzes (49\%) e Suzano (72\%), a delimitação se deu de forma parcial.

As Áreas de Proteção de Mananciais e as Áreas de Proteção e Recuperação de Mananciais são áreas de captação e produtoras de água de interesse regional para abastecimento público no Estado de São Paulo e estão inseridas em uma das Unidades de Gerenciamento de Recursos Hídricos, previstas no Sistema Integrado de Gerenciamento de Recursos Hídricos, instituído pela Lei Estadual $n^{\circ}$ 7.663/1991. Por similaridade, podem ser entendidas como Área de Proteção Ambiental, categoria prevista no SNUC, cujo objetivo é compatibilizar a proteção da diversidade biológica, disciplinar o processo de ocupação e assegurar a sustentabilidade do uso dos recursos naturais.

$\mathrm{Na}$ área desta pesquisa encontram-se algumas unid ades de conservação, dentre elas, destacamse aqui: a Área de Proteção Ambiental da Várzea do Rio Tietê e a Unidade de Conservação Estadual. Dentre outros, possui também objetivos de proteção e recuperação do rio Tietê e do seu entorno, pelo controle de ocupação das várzeas, para minimizar inundações, processos erosivos e assoreamento, causados pela urbanização. Também visa à preservação e recuperação dos remanescentes da biota local. A APA da Várzea do Rio Tietê é uma área protegida que cumpre papel importante não só no Sistema Ambiental Paulista para conservação da biodiversidade, mas sobretudo no Sistema Integrado de Gerenciamento de Recursos Hídricos.

Do ponto de vista da governança dessas áreas, o Sistema Ambiental Paulista reúne a Secretaria Estadual de Infraestrutura e Meio Ambiente, o Conselho Estadual de Meio Ambiente, institutos e fundações, dentre elas, a Fundação Florestal, que é responsável pela gestão das unidades de conservação no Estado de SP. O Sistema Integrado de Gerenciamento de Recursos Hídricos é representado pelo Governo Estadual, os municípios e a socied ade civil, incluind o o Conselho Estadual de Recursos Hídricos e os Comitês de Bacia Hidrográfica.

Para refletir sobre as especificidades da política escalar na governança ambiental e no planejamento territorial no SPAT, é importante identificar os atores e instituições, suas racionalidades e estratégias de atuação no território que definem as múltiplas territorialidades, considerando as principais questões, conflitos, as relações e interesses que mantém com as áreas protegidas, seus discursos e os papéis que ocupam, as relações de poder que são estabelecidas e a relação destes com os recursos naturais.

Um importante ator nesta região é o Consórcio de Desenvolvimento dos Municípios do Alto Tietê (CONDEMAT), que se apresenta como um espaço de gestão pública intermunicipal, de planejamento e cooperação regional para o desenvolvimento sustentável. O CONDEMAT é um consórcio público, que teve sua origem na Associação dos Municípios do Alto Tietê, e que representava os interesses dos municípios junto aos Governos Estadual e Federal. O Consórcio tem como uma de suas principais bandeiras a compensação financeira aos municípios produtores de água ou que possuem restrições de uso e ocupação do solo pelos instrumentos de proteção ambiental. De acord o com Abrúcio e Sydon (2018), os consórcios municipais são uma forma de cooperação vinda do associativismo, onde o território se torna referência a partir da qual se organiza a política pública. 
Se por um lado, neste caso, os municípios articulados em um consórcio tendem à uma maior inserção metropolitana, por outro, é necessário que todos olhem para o território e tenham maior controle quanto à apropriação do espaço, de forma a se gerenciar as transformações advindas dos grandes projetos e empreendimentos na região, como o Rodoanel, o Ferroanel Norte e tantos outros presentes nas agendas governamentais, que podem ser vistos como grandes desafios para se pensar a governança territorial.

Para as áreas protegidas, a governança tem sido questão chave para a compreensão dos arranjos institucionais que se formam para uma maior eficácia. Governança é um conceito multifacetado que reconhece a necessidade de ampliação do número de atores a serem envolvidos na gestão pública, assim se baseia em múltiplos atores, nos objetivos compartilhados, em fronteiras fluidas entre o público e o privado, outras esferas associativas e multiplicidade de formas de ação, intervenção e controle. (Kooiman, 1993; Frey, 2007; Jacobi \& Sinisgalli, 2012).

$\mathrm{Na}$ perspectiva da governança multinível, entendida como a governança entre diferentes esferas governamentais (Abrúcio \& Sydon, 2018), o território das áreas protegidas abriga relações de poder e processos sociais específicos na produção do espaço, no qual o Estado se coloca (ou deveria se colocar) como articulador das políticas públicas para governança ambiental. Alguns instrumentos de planejamento territorial e governança ambiental para gestão dos mananciais nesta região, tais como o Plano de Desenvolvimento e Proteção Ambiental e mesmo os planos de manejo das unidades de conservação, se apresentam como importantes instrumentos para a integração de políticas públicas para a área de estudo, porém é perceptível que pouco dialogam, olhando cada um para o território a partir de sua perspectiva. O Estado, promotor de tais políticas públicas, por muitas vezes tem deixado de garantir esse olhar integrador, que poderia dar respaldo às estratégias de enfrentamento e mesmo mitigação para eventos extremos causados por alterações climáticas.

Do conceito geral de governança, advindo de um período de mudanças dos modelos de planejamento e gestão - de tecnocráticos para mais participativos -, assim como a virada neoliberal, que reduz o papel protagonista do estado, diversas modalidades de governança foram propostas em diversos setores e políticas. Alinhado com as ciências ambientais, o conceito governança adaptativa pode ser interessante, do ponto de vista normativo, na busca de uma modalidade mais inclusiva e reflexiva associada com as mudanças climáticas. Essa governança parte de teorias acerca da resiliência, permite avaliar e gerenciar até que ponto um sistema pode absorver perturbações naturais e humanas recorrentes e continuar a se regenerar (Folke et al, 2005). A definição mais comumente usada para resiliência assume que os sistemas ecológicos operam em/ou perto do equilíbrio global, sendo aquela que possui a capacidade de retornar ao equilíbrio após uma perturbação (Gunderson, 1999).

Entretanto, para Dietz e outros (2003), a governança adaptativa refere-se ao contexto político e social que é parte da gestão dos recursos naturais. Esta abordagem já é usada no planejamento e na governança das unidades de conservação, sua origem está na Biologia da Conservação, conhecida como Gestão Adaptativa de Unidades de Conservação, uma abordagem metodológica baseada no manejo adaptativo, que inclui conceitos comuns para o desenho, o manejo e o monitoramento de projetos de conservação, visando ajudar os que trabalham neste campo a melhorar práticas da conservação. Assim, para as áreas protegidas, a governança adaptativa pode ser entendida como uma abordagem de gestão que reconhece as maneiras como os ecossistemas funcionam, reconhece sua fragilidade e que grande parte da aprendizagem ocorre na tomada de decisão real e execução das decisões e em uma revisão contínua (Borrini-Feyrabend et al. 2015, p.195).

Olhando para alguns instrumentos de planejamento territorial utilizados para as áreas protegidas, tais como planos diretores, planos municipais da mata atlântica, planos de manejo de unidades de conservação, torna-se interessante pensar que estes poderiam ser voltados para se planejar em cenários de complexidades e incertezas, como por exemplo, os das mudanças climáticas.

Serrão-Neumann et al. (2013) afirmam que é importante ter um planejamento alternativo e que existe a necessidade de algumas abordagens nos sistemas de planejamento que possam lidar com \begin{tabular}{|l|l|l|l|l|l|}
\hline Rev. Gest. Soc. Ambient. São Paulo (SP) & v.15 & p.01-17 & e02794 & 2021. \\
\hline
\end{tabular} 
as incertezas. Pautam a adoção de abordagens emergentes de planejamento, apoiadas na governança antecipatória, como uma alternativa para os sistemas de planejamento, capazes de lidar com esses desafios e enfrentar a adaptação às mudanças climáticas. Para os autores, a prática da governança antecipatória tem potencial para ajudar os governos locais. Esse modo de governança prevê uma estrutura de decisão flexível que usa uma gama de futuros possíveis para se preparar para mudanças e guiar as decisões para maximizar as boas alternativas futuras e minimizar ameaças. As etapas envolvidas na estrutura de governança antecipatória podem permitir que o sistema de planejamento lide com os desafios das mudanças climáticas (QUAY, 2010).

\section{MÉTODO}

A pesquisa que dá origem a este trabalho utilizou dados produzidos no âmbito do projeto de pesquisa "Dinâmicas territoriais e transformações na paisagem nas cabeceiras do Tietê" (CNPQ/Universal), assim como o conhecimento empírico adquirido a partir das práticas de planejamento. Considerando o conhecimento e o envolvimento das pesquisadoras na região, e a conjuntura socioambiental e política, realizou-se também pesquisa documental. De acordo com Lakatus (2017), a pesquisa documental corresponde a toda a informação coletada, seja de forma oral, escrita ou visualizada.

A pesquisa baseou-se na coleta de dados qualitativos, nos registros pessoais de trabalho (produtos de planejamentos, relatórios, atas de reuniões, entre outros) e na leitura de documentos públicos, em especial os instrumentos de planejamento territorial, como por exemplo os Planos Diretores dos municípios analisados, o Plano de Desenvolvimento e Proteção Ambiental (PDPA) da Área de Proteção e Recuperação de Mananciais do Alto Tietê-Cabeceiras, o Plano de Manejo APA da Várzea do Rio Tietê (etapa diagnóstico) e o arcabouço legal que trata das unidades de conservação e das áreas de mananciais. Documentos organizacionais formam parte da realidade documental na qual e através da qual as organizações, ambientes sociais e vidas são representadas, vividas e contadas (COFFEY, 2014).

Também foram considerados os registros pessoais de participações em reuniões, debates, oficinas de trabalho para elaboração tanto do Plano de Manejo da APAVRT, quanto do PDPA TietêCabeceiras, durante a construção dos documentos analisados, da mesma forma, como anotações em reuniões do Conselho Gestor da APA da Várzea do Rio Tietê, Comitês de Bacia Hidrográfica, participando como conselheiras nestes fóruns, além de participações como convidada em reuniões da Câmara Técnica de Gestão Ambiental do CONDEMAT. Coffey (2014) nos lembra também que os registros textuais também incorporam ações individuais, interações e encontros em ambientes sociais.

Tratou-se assim de um estudo de caso sobre a aplicação dos instrumentos de planejamento territorial e de governança ambiental, em especial as áreas protegidas, que analisou os impactos e transformações presentes nos processos de produção do espaço e a eficácia da legislação ambiental estabelecida para as unidades de conservação, no Sistema Produtor do Alto Tietê. O estudo de caso, muito aplicado às ciências ambientais, tem como finalidade descrever casos específicos relacionados à teoria. Segundo Gil (1999), tal método pode muitas vezes ser limitado, considerando a falta do rigor metodológico, mas o mesmo não invalida a pesquisa desenvolvida. É um tipo de projeto em pesquisa qualitativa que pode ser considerado objeto de estudo ou objeto de investigação (CRESWELL, 2014).

\section{RESULTADOS E DISCUSSÕES}

As unidades de conservação, assim como as áreas de proteção de mananciais, são locais protegidos, entendidos como instrumentos de governança que estão presentes não apenas na política ambiental, mas também na política urbana e demais processos de planejamento territorial como pode 
Duarte dos Santos, S. A. ., Momm Schult, S., Travassos, L. R. F. C. ., \& Fernandes, B. de S. . (2021). As Áreas Protegidas do Sistema Produtor do Alto Tietê: A Governança e o Planejamento em Cenários de Mudanças Climáticas.

ser observado nos planos diretores. As seções seguintes tratam sobre os processos de governança das áreas protegidas do SPAT, apresentando cada uma delas e os conflitos presentes nestes territórios.

\subsection{Os processos de governança das áreas protegidas}

Dentro de um processo histórico de proteção dos mananciais hídricos no estado de São Paulo, a primeira Legislação de Proteção aos Mananciais (Leis Estaduais $n^{\circ}$ 898/75 e $n^{\circ} 1.172 / 76$ ) caracterizou-se por apresentar centralismo e ausência de sistemas que pudessem gerir tais espaços, mostrando-se ineficaz no que diz respeito ao tratamento da ocupação irregular destas áreas. A Lei Estadual n $n^{\circ}$ 9.866/97 trouxe um novo modelo de política de proteção aos mananciais, valorizando a proteção e recuperação das condições ambientais imprescindíveis para produção de água, com a criação e delimitação de Áreas de Proteção e Recuperação de Mananciais e Áreas de Intervenção. Além do objetivo de preservar e recuperar mananciais, a nova lei trouxe a proposta de compatibilizar ações de preservação e proteção com uso e a ocupação do solo e desenvolvimento econômico, com o intuito de integrar programas e políticas habitacionais à preservação ambiental. Propôs também a gestão participativa, que incorpora outros níveis de poder, além do poder público, possibilitando novos olhares e contribuições ao território, no entanto, tem se mostrado pouco eficaz.

A Lei $n^{\circ}$ 9.866/97 reconhece a dinâmica de ocupação existente em toda a região de mananciais, apresenta proposições para o desenvolvimento com proteção ambiental e garante ainda um aporte financeiro para a implementação da política de proteção dos mananciais, com recursos oriundos dos orçamentos estaduais e municipais e da cobrança pelo uso da água. Compatibiliza ações de uso do solo com ações ambientais, permitindo o planejamento regional para soluções de problemas comuns aos municípios. Com relação às políticas setoriais, possibilita o compartilhamento de uma política habitacional com a de proteção dos recursos naturais, utilizando-se de instrumentos como o Plano de Desenvolvimento e Proteção Ambiental, Áreas de Intervenção, Compensação Financeira aos Municípios, entre outros. Tem ainda, como um de seus objetivos, a promoção da gestão participativa e a descentralização. A lei propõe a atuação de forma compartilhada com os municípios no que diz respeito ao monitoramento da qualidade da água e fiscalização, cabend o aos municípios o controle do uso do solo e a possibilidade de implantar um sistema de licenciamento municipal, em consonância com o Comitê de Bacia, já que ao mesmo é dada a incumbência de emitir pareceres em relação a empreendimentos de impacto regional e/ou que exijam compensação ambiental.

Em um período marcado por eventos climáticos extremos, o comprometimento da disponibilidade hídrica dos mananciais do Alto Tietê Cabeceiras, relaciona-se diretamente à forma como o espaço vem sendo produzido e demanda instrumentos para o enfrentamento de situações complexas e das várias incertezas, por meio de ações de adaptação, que garantam segurança hídrica. Neste sentido, o estabelecimento da APRM do Alto Tietê-Cabeceiras, pela Lei Estadual $\mathrm{n}^{\circ}$ 15.913/2015, que possui dentre seus objetivos o de assegurar e potencializar a função do SPAT como provedor de água prioritariamente para abastecimento público, pode contribuir para a segurança hídrica da região, garantindo água em qualidade e quantidade, assim como viabilizando a compensação financeira aos municípios.

Entretanto, as Áreas de Proteção de Mananciais e as Áreas de Proteção e Recuperação de Mananciais, seguem vulneráveis a impactos ambientais por ocupação irregular, desmatamento ilegal, uso de agrotóxicos, etc. As Áreas de Proteção de Mananciais anteriormente criadas, acabaram sendo espaços contraditórios, pois eram extremamente restritivas no que se refere à ocupação. Ao mesmo tempo em que não possuíam, no escopo de sua base legal, a previsão de desapropriação de terras para que fosse garantida proteção total ou instrumentos de gestão que permitissem intervir nas dinâmicas territoriais existentes, ou mesmo que tal ferramenta pudesse ser usada pelo poder público para garantir a proteção destas áreas. Vale lembrar que o estabelecimento de Áreas de Proteção e Recuperação de Mananciais traz uma nova forma de gestão para estes territórios produtores de água. 
É importante comentar que a IUCN desenvolveu um sistema de classificação para as áreas protegidas no qual existe uma categoria baseada na definição de zonas de uso múltiplos de recursos, consoante uma nova visão de áreas protegidas enquanto espaços estratégicos para a busca da condição de vida adequada. Esta categoria objetiva a administração dos elementos para a produção sustentada da água, entre outros elementos de provisão necessários à satisfação das necessidades econômicas e sociais e poderia ser uma nova categoria de unidade de conservação a ser incluída no SNUC, dando amparo às APRM e outras formas de proteção.

\subsection{As áreas protegidas do Sistema Produtor do Alto Tietê-SPAT}

Os municípios abrangid os pelo SPAT: Mogi das Cruzes, Suzano, Biritiba-Mirim e Salesópolis (figura $\mathrm{n}^{\circ}$ 1) foram total ou parcialmente delimitados como mananciais de interesse público pela Lei de Proteção aos Mananciais (Leis Estaduais n 895/75 e 1.172/76), que estabeleceu Áreas de Proteção de Mananciais nas bacias de 4 (quatro) reservatórios destinados à produção de água e redução de vazões à jusante, o que possibilitou a preservação de alguns atributos naturais na região.

A delimitação abrangeu quase $100 \%$ do território em alguns municípios do SPAT, tais como BiritibaMirim (89\%) e Salesópolis (98\%) e no caso de Mogi das Cruzes (49\%) e Suzano (72\%) a delimitação se deu de forma parcial.

No SPAT existem quatro Unidades de Conservação Estaduais, que abrangem os Municípios de Mogi das Cruzes, Suzano, Biritiba-Mirim e Salesópolis (ver tabela no ${ }^{\circ}$ ), sendo: Parque Estadual da Serra do Mar (PESM), APA da Várzea Rio Tietê (APAVRT), APA da Serra de Itapeti e Estação Ecológica de Itapeti, além de estarem todos estes também inseridos na Reserva da Biosfera do Cinturão Verde da Cidade de São Paulo (RBCV).

Quanto às Unidades de Conservação Municipais, Mogi das Cruzes vem trabalhando com este instrumento em âmbito local e instituiu as seguintes: Parque Natural Municipal (PNM) Francisco Afonso de Melo, Reserva Particular do Patrimônio Natural (RPPN) Botujuru-Serra de Itapeti, RPPN Hinayana e RPPN Mahayana. A proteção neste município abrange cerca de 57\% de seu território, sendo: $49 \%$ em áreas de mananciais e o restante em outras categorias de áreas protegidas. Outro município que também vem implantando Unidades de Conservação Municipal é Suzano, com a criação do Parque Natural Municipal (PNM) Mirante do Sesc (em construção).

As unidades de conservação localizadas nos municípios que integram o SPAT são apresentadas na figura $n^{\circ} 02$ e estão organizadas na tabela $n^{\circ} 01$ :

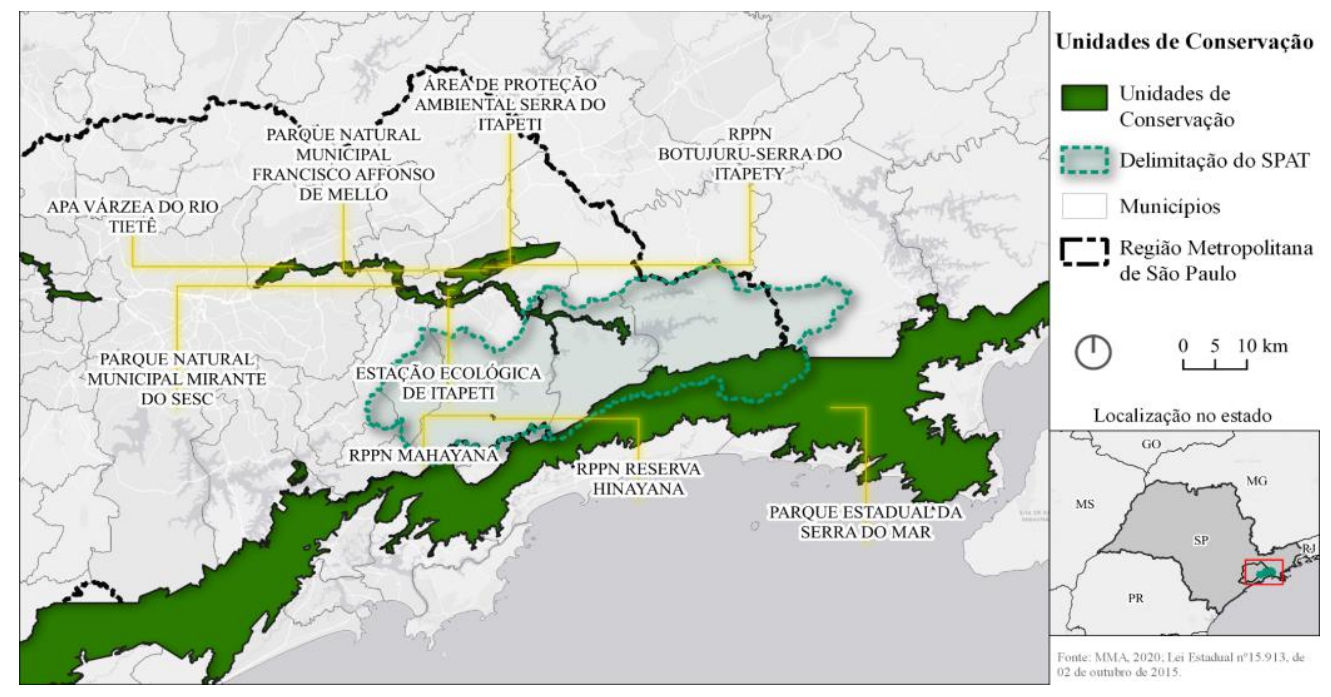

Figura $n^{\circ} 02$ - Unidades de Conservação do SPAT. Fonte: LAPLAN, Bruna Fernandes, 2021. 
É importante destacar o crescimento das Unidades de Conservação Municipais após o SNUC, uma estratégia para se assumir o compromisso de conservação da biodiversidade na esfera local, considerando as condicionantes socioeconômicas e as tendências atuais de ocupação humana no território e propondo ações estratégicas que considerem a importância da conservação dos recursos naturais. Na composição e articulação destes territórios, os governos locais tem papel legítimo na gestão das áreas protegidas, bem como na proposição e gestão de outras medidas de conservação. Porém, com grande frequência, o debate sobre estes espaços fica à margem dos planejamentos e estratégias de desenvolvimento territorial nos municípios. Muitas vezes são inexistentes as informações sobre a importância das áreas protegidas existentes e o papel que estas cumprem na prestação de serviços ambientais, mitigação dos efeitos das mudanças climáticas e como podem direcionar o planejamento territorial numa dada região para que se garanta bem-estar.

No caso da RBCV, trata-se de uma das seis Reservas da Biosfera existentes no Brasil e abrange as unidades de conservação, e demais áreas protegidas nelas inseridas, em 78 municípios, dentre eles os municípios do SPAT. Considera a legislação local, os limites das unidades de conservação, APMs, APRMs, a Lei da Mata Atlântica, Código Florestal entre outros. Seu objetivo é integrar as áreas prioritárias para conservação com outras de usos diferenciados, com diversos níveis de interferência humana, promovendo o desenvolvimento sustentável a partir de sistemas de governança inovadores e participativos (Rodrigues, Victor e Barradas, 2020). Possui um Conselho de Gestão- que além de promover a conservação ambiental por meio de apoio e incentivo para criação de novas unidades de conservação e outras áreas protegidas, também se manifesta analisando a implantação de empreendimentos que causem significativo impacto ambiental no território, o que fortalece muito a governança das áreas protegidas em âmbito local, já que tais manifestações devem ser levadas em consideração pela gestão municipal.

Tabela $n^{\circ} 01$ - As áreas protegidas existentes nos Municípios do Sistema Produtor do Alto Tietê

\begin{tabular}{|c|c|c|c|c|}
\hline \multicolumn{5}{|c|}{ ÁREAS PROTEGIDAS NO SPAT } \\
\hline & Salesópolis & Biritiba-Mirim & Suzano & Mogi das Cruzes \\
\hline & & & $\begin{array}{l}\text { PNM Mirante do } \\
\text { Sesc }\end{array}$ & $\begin{array}{l}\text { PNM Francisco } \\
\text { Afonso de Melo }\end{array}$ \\
\hline \multirow[t]{3}{*}{ UC's Municipais } & & & & $\begin{array}{l}\text { RPPN Botujuru- } \\
\text { Serra de Itapeti }\end{array}$ \\
\hline & & & & RPPN Hinayana \\
\hline & & & & RPPN Mahayana \\
\hline \multirow{4}{*}{ UC's Estaduais } & PESM & PESM & & PESM \\
\hline & & & & ESEC Itapeti \\
\hline & APAVRT & APAVRT & APAVRT & APAVRT \\
\hline & $\begin{array}{l}\text { APA Serra de } \\
\text { Itapeti }\end{array}$ & & $\begin{array}{l}\text { APA Serra de } \\
\text { Itapeti }\end{array}$ & $\begin{array}{l}\text { APA Serra de } \\
\text { Itapeti }\end{array}$ \\
\hline Categoria Internacional & RBCV & $\mathrm{RBCV}$ & RBCV & RBCV \\
\hline
\end{tabular}

Fonte: Elaborado pelas autoras, 2021. 
Duarte dos Santos, S. A. ., Momm Schult, S., Travassos, L. R. F. C. ., \& Fernandes, B. de S. . (2021). As Áreas Protegidas do Sistema Produtor do Alto Tietê: A Governança e o Planejamento em Cenários de Mudanças Climáticas.

É possível identificar nas políticas urbanas de cada um dos municípios do SPAT, tais como os planos diretores e a inserção do tema áreas protegidas no planejamento territorial. Suzano estabeleceu, em seu Plano Diretor (LC no 312/2017), a Macrozona da APA do Tietê, que corresponde à porção do território compreendido dentro da unidade de conservação estadual, garantindo os parâmetros e critérios de uso, ocupação e parcelamento do solo estabelecidos pela legislação estadual pertinente.

O Plano Diretor de Mogi das Cruzes (LC no 150/2019), destacou em seu texto a importância das áreas protegidas, apresentando entre seus objetivos o de promover o patrimônio ambiental do Município, valorizando a biodiversidade e o reconhecimento dos serviços ambientais prestados por essas áreas (art. $5^{\circ}$ - V). Além de determinar que a legislação de parcelamento, uso e ocupação do solo municipal deverá ser revista, compatibilizando com os planos de manejo das unidades de conservação, o que permite o diálogo entre um instrumento de política urbana com instrumento de conservação ambiental (art. 50 - XIV):

O município de Biritiba-Mirim definiu, em seu Plano Diretor, a importância da APRM ATC, quando determinou que é competência municipal dotar o Município de uma visão própria de desenvolvimento sustentável e plenamente compatível com a preservação da qualidade das águas do manancial, de forma a instrumentalizar o poder público municipal para participar ativamente do processo de elaboração da lei estadual específica da Bacia Hidrográfica (LC no 05/2004, art 6-IX). Salesópolis, em seu Plano Diretor (LC n ${ }^{\circ}$ 09/2018), incluiu no ordenamento territorial as categorias de áreas de intervenção elencadas na Lei Estadual $n^{\circ}$ 15.913/2015, que estabeleceu a APRMATC, classificando o Parque Estadual da Serra do Mar como Área de Restrição à Ocupação (ARO) (art. 13 - $\left.\S 1^{\circ} \mathrm{III}\right)$.

Aind a assim, a forma como vem se dando a ocupação nestes territórios e como estes espaços vem sendo produzidos, tem comprometido a qualidade ambiental nas áreas protegidas, afetando a quantidade e a qualidade dos recursos hídricos. Expansão urbana e impactos de grandes empreendimentos, uso de defensivos agrícolas e agronegócio, atividades de mineração, entre outros, se apresentam como importantes desafios para a governança do território do SPAT.

\subsection{Análise dos conflitos e desafios da governança e do planejamento na área de estudo}

A partir de alguns estudos mais recentes sobre a região, com foco na proteção ambiental, tais como o Plano de Desenvolvimento de Proteção Ambiental, 2014, revisado em 2018 e o Plano Manejo da APA da Várzea do Rio Tietê, 2013 (ainda sem decreto de aprovação), foi possível não só verificar a grande interface dos recursos hídricos (água) com as áreas protegidas, mas também identificar alguns conflitos nos municípios do SPAT que vem transformando estes espaços sob proteção. Dentre os conflitos, é possível citar: expansão urbana sobre áreas de mananciais, impactos de grandes empreendimentos: Rodoanel (impacto nas várzeas do rio Tietê, Suzano), projeto de implantação do Hidroanel (Mogi e Suzano) e do Ferroanel (Suzano): alteração no uso do solo, conflitos sociais, desmatamentos, além do uso de agrotóxicos e defensivos agrícolas comprometendo recursos hídricos. O agronegócio, especificamente, é uma atividade em expansão na região e grande parte do território do SPAT tem uso predominantemente agrícola, com produção de hortifrutigranjeiros, flores e frutas, sendo a região conhecida como Cinturão Verde. No entanto, o uso de defensivos agrícolas é contraditório com a proteção dos mananciais, sendo importante e urgente o desenvolvimento de ações que considerem a transição ecológica.

Mogi das Cruzes tem uso predominante agrícola, mas também é o maior parque industrial dentre os municípios do SPAT (cerca de 140 indústrias), bem como possui algumas áreas contaminadas por atividades de mineração. Quanto à proteção do território de Mogi das Cruzes, o zoneamento municipal estabeleceu uma zona de uso rural-urbano que se sobrepõe à zona de cinturão meândrico da APA da Várzea do Rio Tietê. A Zona de Cinturão Meândrico - ZCM compreende as 
faixas de terrenos de planícies aluvionares do rio Tietê, que tem por finalidade o controle das inundações, sendo vedadas nestas áreas atividades industriais, minerárias, habitação entre outras.

Suzano é o município que mais apresenta conflitos quanto à proteção ambiental, tanto no que se refere às Áreas de Proteção e Recuperação de Mananciais quanto às unidades de conservação. A expansão urbana tem se dado sobre as áreas protegidas com grande adensamento. Conta também com expressiva produção agrícola e com grande número de indústrias (43 unidades), atividades de mineração e algumas áreas contaminadas, além de intervenção nas planícies de inundação do rio Tietê por obras do Rodoanel.

Vallim (2019) ao estudar o SPAT, identificou no município de Biritiba-Mirim atividades como a silvicultura que atende as indústrias da construção civil assim como a presença de ranchos e clubes de lazer, ao longo das áreas de proteção de mananciais, como medida adotada aos longo dos anos para impulsionar o turismo na região, fato este que está atrelado à oferta dos recursos hídricos para atividades de recreação, pesca, dentre outros, mas que, sem efetivo controle, podem ter grande possibilidade de comprometimento dos cursos d'água e degradação da vegetação nativa.

De acordo com os estudos desenvolvidos por Travassos et al (2020), existem claros indicativos de incentivos para a ampliação e adensamento das áreas urbanas, propondo maior aproveitamento do potencial construtivo e ampliação das atividades dos setores de comércio e serviços em um polígono maior no eixo principal de Biritiba Mirim, com pouca aderência à realidade do município

Segundo estudos de revisão do PDPA (2014), foram verificados alguns vetores de pressão na região, tais como crescimento de borda nos municípios de Mogi das Cruzes, Suzano, Biritiba Mirim e Salesópolis; observando-se também em Biritiba Mirim e Salesópolis, o surgimento de loteamentos de chácaras e condomínios na periferia. Os adensamentos resultantes dessas pressões urbanas ocorrem em áreas próximas às principais rodovias e artérias que cortam o território da APRM.

É possível também perceber que, independente da escala, os conflitos se repetem e, na sua grande maioria, apontam para a gestão integrada como caminho essencial para a conservação dos recursos hídricos, a gestão de áreas protegidas e do uso da terra, aliados a um processo de gestão participativa. Assim, a constituição de espaços institucionalizados, de tomada de decisões, como conselhos, comitês, são verdadeiros instrumentos de representação, expressão e participação popular na gestão dos bens públicos, bem como no exercício da cidadania, considerada boa prática de governança. Esses espaços tem a possibilidade de ser verdadeiras arenas de negociação e poder dentro das estruturas de governança, nas quais os conflitos podem surgir como formas de legitimar as diferentes visões de mundo. Reconhecer os conflitos é o primeiro passo para uma ação transformadora nestes casos.

A região se apresenta como um espaço com grandes desafios, já que é importante produtora de água, mas também plena de possibilidades, os mananciais são ativos ambientais com grande potencial de implantar programas de Pagamento por Serviços Ambientais, o que já vem acontecendo no município de Salesópolis desde 2014, a partir de um programa coordenado pela Organização Não Governamental The National Conservancy (TNC). Essa instituição coordena o Painel Conservação e Recuperação de Mananciais, com abordagem sobre Pagamento por Serviços Ambientais e, no Brasil, selecionou 12 áreas prioritárias para aplicação do programa, dentre estas Salesópolis, Biritiba-Mirim e Mogi das Cruzes.

Ao mesmo tempo, o poder público municipal cobra do Estado a possibilidade de levar para região novos empreendimentos em sua maioria impactantes, o que é contraditório com a proposta de conservação dos territórios produtores de água. Eventos extremos como longos períodos de seca, inundações, deslizamentos entre outros estão presentes na região do SPAT, muitas vezes marcados pela forma de apropriação do espaço, pela expansão da ocupação sobre as áreas protegidas. Neste sentido, talvez o grande desafio para este território seja a gestão ad aptativa em espaços protegidos, de forma a contribuir com o enfrentamento às mudanças no clima. 
A Lei Específica para os Mananciais, o Plano de Desenvolvimento e Proteção Ambiental (PDPA), além dos planos de manejo das Unidades de Conservação desta região e as propostas de gestão da mesma, além de se apresentarem como novos instrumentos de planejamento territorial também se mostram uma grande proposta de políticas públicas de integração para tal área de estudo. Porém, é perceptível que as estruturas de governança, tais como o CONDEMAT, os conselhos de Unidades de Conservação, os Comitês de Bacias, órgãos gestores e os poderes públicos municipais, pouco dialogam, olhando cada uma para o seu território dentro de uma visão desarticulada.

\section{CONSIDERAÇÕES FINAIS}

É essencial ratificar a importância regional da área de estudo e quão grande são os desafios de gestão da mesma. Desafios para uma região que pode ser considerada espaço integrador da biodiversidade, sistema produtor de águas, espaço gerador de renda por meio de atividades que protegem e valorizam seus atributos naturais, históricos e culturais e espaço que oportuniza a gestão participativa. No entanto, na ausência de uma perspectiva ampla da compreensão da importância de seu papel no desenvolvimento, advoga-se como uma grande "arena" para concretização de processos de desenvolvimento econômico, muitas vezes relacionados a outras escalas, que criam novas dinâmicas e geram impactos locais e degradação.

O conceito de governança vem sendo utilizado em diversas esferas, em muitos momentos e situações, podendo a governança ambiental ser reconhecida dentro do debate das questões socioambientais. A governança de áreas protegidas tem sido tema chave para o aperfeiçoamento e efetividade dos objetivos atrelados a estes espaços e o conceito e princípios difundidos por Graham et al (2003), legitimidade e voz, direcionamento, desempenho, prestação de contas e equidade, respectivamente, podem ser aplicados tanto na gestão das unid ades de conservação quanto das áreas de mananciais, considerando as especificidades e objetivos de cada um dos grupos.

As mudanças climáticas e seus efeitos são realidade sensíveis no SPAT, assim, é importante pensar em estratégias específicas de mitigação e adaptação, que considerem sobretudo os impactos socioambientais. Portanto, esse tema deverá estar presente nos vários instrumentos existentes e ser central para a sua integração. No entanto, não é possível identificar movimentos significativos que convertam os atuais sistemas e práticas de planejamento em uma perspectiva mais adaptativa e antecipatória.

É possível também afirmar que, tantos as Áreas de Proteção e Recuperação de Mananciais, quanto às unidades de conservação são instrumentos que interferem na gestão do território e que deveriam se apresentar como articulad ores e integrad ores para proteção ambiental e desenvolvimento sustentável, no entanto, são permeados de conflitos que precisam ser explicitados para permitir uma melhor compreensão dos desafios de governança existentes.

Para refletir as especificidades da política escalar na governança ambiental e no planejamento territorial na região, é importante conhecer as instituições, atores e colegiados que atuam no território, quais as principais questões, conflitos, as relações e interesses que mantém com as áreas protegidas, seus discursos e os papéis que ocupam, as relações de poder que são estabelecidas no planejamento e governança do território. Neste contexto, o CONDEMAT, o Subcomitê do Alto Tietê-Cabeceiras e os Conselhos das Unidades de Conservação, são atores importantes que precisam ser analisados, conhecendo suas agendas, sobreposição, lacunas, como se relacionam, entre outros aspectos. Possivelmente este é um caminho para se entender como as dinâmicas territoriais influenciam o planejamento territorial e a governança ambiental nesta importante região.

O presente texto não tem a pretensão de esgotar as análises dos processos de planejamento e governança das áreas protegidas no território analisado, porém tenta cumprir seu objetivo na medida em que aponta os conflitos e os instrumentos disponíveis para a gestão das áreas protegidas no SPAT. 
Nota: este texto foi adaptado de uma versão originalmente a presentada no IX Seminário Brasileiro sobre Áreas Protegidas e Inclusão Social e IV Encontro Latino Americano sobre Áreas Protegidas e Inclusão Social, ocorrido em dezembro de 2019, em Recife, PE. É resultante dos seguintes projetos de pesquisa: 1) Projeto Temático - Governança Ambiental da Macrometrópole Paulista (Macroamb) - Processo FAPESP nº 2015/03804-9 e 2) Conselho Nacional de Desenvolvimento Científico e Tecnológico - CNPq-Brasil. Edital Universal - Processo: 409061/2016.

\section{REFERÊNCIAS}

Abrúcio, F. L. \& Sydow, C. T. Federalismo e Governança Multinível em Regiões Metropolitanas: O Caso Brasileiro (2018). In: J. M. B. CARNEIRO \& K. FREY (org.) Governança Multinível e Desenvolvimento Regional Sustentável: Experiências do Brasil e Alemanha. Oficina Municipal, SP.

Bensusan, N. (2006). Conservação da Biodiversidade em Áreas Protegidas. Rio de Janeiro, RJ, Brasil. Editora FGV.

Biritiba-Mirim (Município). Lei Complementar nº 05, de 26 de novembro de 2004. Plano Diretor do Município de Biritiba Mirim. Biritiba Mirim, SP, 2004.

Borrini-feyerabend, G. \& Hill, R. (2015) Governance of the conservation of nature. In G. L. Worboys, M. Lockwood, and A. Kothari (ed.), Protected Area Governance and Management, Chapter: 7, Publisher: ANU Press, Canberra (pp.170-205). Recuperado em: 01 de março de 2021, de: https://www.researchgate.net/publication/279197380_Governance_of_the_conservation_of_ nature.

Brasil. Lei Federal no 9.985, de 18 de julho de 2000. Sistema Nacional de Unidades de Conservação da Natureza. Recuperado em: 02 de março de 2021, de: http://www.planalto.gov.br/ccivil_03/leis/19985.htm.

Brasil. Decreto Federal no 5.758, de 13 de abril de 2006. Plano Estratégico Nacional de Áreas Protegidas - PNAP. Recuperado em: 20 de dezembro de 2021, de: https://antigo.mma.gov.br/estruturas/205/_arquivos/planonacionaareasprotegidas_205.pdf

Brasil. Lei Federal no 12.651, de 25 de maio de 2012 Novo Código Florestal. Recuperado em: 02 de março de 2021, de: http://www.planalto.gov.br/ccivil_03/_ato2011 2014/2012/lei/l12651.htm.

Coffey, A. Analysing Documents (2014). In: U. Flick (ed) The Sage Handbook of Qualitative Data Analysis. Grã-Bretanha (pp. 367-379).

Creswell, J. W. (2014). Investigação Qualitativa e Projeto de Pesquisa. (3ª ed.) Porto Alegre: Penso.

Dietz, T., Ostrom, E. \& Stern, P. C. (2003) The struggle to govern the commons. Science. 302 (5652):1907-1912.

Folke, C., Hahn, T., Olsson, P. \& Norberg, J. (2005). Adaptive governance of social-ecological systems. Annual Review of Environment and Resources. 30: 441-473. 
Gil, A. C. (1999). Métodos e Técnicas em Pesquisa Social. (5 ed.). Editora Atlas.

Graham, J., Amos, B., \& Plumptre, T. (2003). Governance principles for protected areas in the 21st century. Prepared for The Fifth World Parks Congress Durban, South Africa. Ottawa, ON: Institute on Governance.

Gunderson, L. (1999). Resilience, flexibility and adaptive management: antidotes for spurious certitude. Conservation Ecology. 3(1):7.

Frey, K. (2007). Governança Urbana e Participação Pública. ANPAD. Rac-Revista Eletrônica. v. 1, n. 1 , art. 9, p. 136-150.

Holling, C. S. (1978). Adaptive environmental assessment and management. John Wiley \& Sons (ed). London, $402 \mathrm{p}$.

Jantz, P., Goetz, S \& Laporte, N. (2014). Carbon stock corridors to mitigate climate change and promote biodiversity in the tropics. Nature Climate Change. 4: 138-142.

Jacobi, P. R. (2005). Ampliação da Cidadania e Participação - desafios na redemocratização do poder público - sociedade civil no Brasil. Universidade de São Paulo.

Jacobi, P. R. \& Sinisgalli, P. A. A. (2012). Governança Ambiental e Economia Verde. Ciência \& Saúde Coletiva, Rio de Janeiro, v. 17, nº 6, pp. 1469-1478.

Kooiman J. (1993). Modern Governance. New Government-Society Interactions. London: Sage.

Lakatos, E. M. \& Marconi, M. A. (2017). Metodologia do trabalho científico: projetos de pesquisa, pesquisa bibliográfica, teses de doutorado, dissertações de mestrado, trabalhos de conclusão de curso. ( $8^{\mathrm{a}}$ ed.) - São Paulo: Atlas.

Mogi das Cruzes (Município). Lei Complementar no 150, de 26 de dezembro de 2019. Plano Diretor do Município de Mogi das Cruzes. Mogi das Cruzes, São Paulo, 2010.

Moom, S., Bohn, N. \& Kanil, K. (2021). Área de preservação permanente e o papel dos municípios no ordenamento territorial e na gestão de recursos híd ricos e do risco. In. S. CRESTANA, E. G. Castellano \& A. Rossi. (orgs.). Espaços Especialmente Protegidos e o Direito Ambiental. Embrapa, Brasília, DF, v. 4, pp. 503-522.

Quay, R. (2010). Anticipatory Governance. Journal of the American Planning Association. 76(4):496-511.

Rodrigues, E. A., Victor, R. A. B. M \& Barradas, A. M. F. (2020). Um cinturão de vida ao redor de São Paulo. In: E. A. Rodrigues, R. A. B. M. Victor, B. C. C. Pires, E. F. de Luca (ed.), Serviços Ecossistêmicos e Bem-Estar Humano na Reserva da Biosfera do Cinturão verde da Cidade de São Paulo. São Paulo: Instituto Florestal.

São Paulo (Estado). Projeto PDPAs RMSP: Plano de Desenvolvimento Regional dos Mananciais do Subcomitê Alto Tietê Cabeceiras: Plano de Desenvolvimento de Proteção Ambiental (PDPA) e assessoria para elaboração das respectivas Leis Específicas (Relatório Técnico). COBRAPE 
e Instituto de Pesquisas Tecnológicas (IPT). Volume 2 e 3, 2014. Recuperado em: 03 de março de 2021, de: http://pdpa.cobrape.com.br/Arquivos/Pdpas/PDPA-Alto-Tiete-Cabeceiras.pdf.

São Paulo (Estado). Lei Estadual no 15.913, de 02 de outubro de 2015. Área de Proteção $e$ Recuperação dos Mananciais do Alto Tietê Cabeceiras - APRMATC, suas Áreas de Intervenção. Recuperado em: 01 de março de 2021, de:

https://www.al.sp.gov.br/repositorio/legislacao/lei/2015/lei-15913-02.10.2015.html.

São Paulo (Estado). Lei Estadual de Mananciais._Recuperado em 01 de março de 2021, de https://www.al.sp.gov.br/repositorio/legislacao/lei/1997/lei-9866-28.11.1997.html.

São Paulo (Estado). Lei Estadual n ${ }^{0}$ 7.663, de 30 de dezembro de 1991. Política Estadual de Recursos Hídricos e Sistema de Gerenciamento Integrado de Recursos Hídricos. Recuperado em: 19 de abril de 2017, de: https://www.al.sp.gov.br/repositorio/legislacao/lei/1991/alteracao-lei7663-30.12.1991.html.

São Paulo (Estado). Plano de Manejo da APA da Várzea do Rio Tietê - Diagnóstico. (2013). Fundação Florestal e Universidade de São Paulo, Volume Principal. São Paulo, SP.

Salesópolis (Município). Lei Complementar no 09, de 19 de abril de 2018. Revisão do Plano Diretor Participativo da Estância Turística de Salesópolis. Salesópolis, SP, 2018.

Serrão-Neumann, S. et al (2013). The Role of Anticipatory Governance in Local Climate Adaptation: Observation from Australia. Planning Practice \& Research, 28:4, 440-463.

Suzano (Município). Lei Complementar no 312 de 22 de dezembro de 2017. Plano Diretor do Município de Suzano. Suzano, São Paulo, dezembro de 2017.

Vallin, E. M. (2019). Dinâmicas Territoriais no Sistema Produtor Alto Tietê. Dissertação (Mestrado em Planejamento e Gestão do Território). Universidade Federal do ABC (UFABC).

Walters, C. (1986). Adaptive Management of Renewable Resources, Macmillan. New York. 388 p.

Travassos, L. R. F. C.; Zioni, S. M.; Momm, S.; Fernandes, B. S.; Portes, B. C. N.; Angelo, D.; Vallim, E. M.; Souza, E. S. L.; Araujo, G M \& Duarte, S. (2016). Dinâmicas territoriais e transformações na paisagem nas cabeceiras do Alto Tietê, 2020. (Relatório de pesquisa) CNPq Edital Universal. 